\title{
Biochemical and clinical studies of Friedreich's ataxia
}

\author{
P PURKISS, M BARAITSER, O BORUD, AND R A CHALMERS \\ From the Division of Inherited Metabolic Diseases, Medical Research Council, \\ Clinical Research Centre, Watford Road, Harrow, England
}

S U M MARY A series of biochemical tests aimed at elucidating the fundamental cause has been applied to 20 patients with Friedreich's ataxia. Special emphasis was placed upon pyruvate metabolism. The results demonstrate no precisely identifiable defect in the metabolism of pyruvate but indicate an abnormality in glucose uptake and metabolism.

The unusually high frequency of occurrence of diabetes mellitus with Friedreich's ataxia and the presumption that many recessive disorders will be found to be associated with detectable enzyme deficiencies has led to Friedreich's ataxia being considered as an inherited metabolic disease. ${ }^{1}$ However, despite extensive investigations by numerous workers, this cerebellar ataxia has resisted precise biochemical definition. ${ }^{23}$

In 1974 Kark et $a l^{4}$ reported that muscle from a third of patients with an inherited ataxia of the Friedreich type oxidized pyruvic acid more slowly than normal controls. Subsequently, a possible deficiency of the pyruvate and the 2-oxoglutarate dehydrogenase complexes affecting the common third enzyme of the complexes has been postulated by Blass et al. ${ }^{50}$ Alternatively a kinetic abnormality of the enzyme lipoamide dehydrogenase could account for the observations. ${ }^{78}$ These results have not been confirmed by others ${ }^{7}$ and it is still unclear whether defects in pyruvate oxidation or lipoamide dehydrogenase occur in patients with "classical" Friedreich's ataxia. Abnormalities of amino acid metabolism especially of taurine and aspartic acid, alterations in high density lipoprotein composition of serum ${ }^{9}$ and hyperbilirubinaemia $^{10}$ have all been suggested but these, when they occur, are secondary effects and the primary defect has not yet been found. Mitochondrial energy deprivation due to altered phospholipids in the inner mitochondrial membrane has recently

Address for reprint requests: P Purkiss, Division of Inherited Metabolic Diseases, MRC Clinical Research Centre, Watford Road, Harrow HA1 3UJ, England.

Accepted 22 May 1981 been suggested as a basic cause of the disorder. ${ }^{11}$ The present study was designed to reinvestigate some aspects of metabolism in Friedreichs' ataxia in a controlled in-patient environment with careful selection of only those patients diagnosed on clinical, genetical and physiological grounds as having Friedreich's ataxia.

\section{Patients and methods}

Twenty patients were chosen for the study using the following criteria as evidence for the diagnosis of Friedreich's ataxia. All except one of the patients had an onset before the age of 20 years and all developed an ataxia of gait which was without remissions. Dysarthria of a cerebellar type developed during the early stages of the illness. Posterior column loss, especially for vibration and position sense, and absent tendon reflexes in the lower limbs were mandatory requirements for inclusion. A young population was specifically chosen and those with severe known diabetes or signs of severe cardiac disease were excluded from the study. Patients were admitted, two at a time, to a metabolic ward for a period of five days during which the clinical, biochemical, immunological haematological and other tests outlined below were carried out.

\section{Clinical assessment}

Each patient had a standard clinical and neurological assessment followed by a radiograph of the whole vertebral column to detect minor degrees of scoliosis that could not be detected clinically, and an ECG. A more detailed electrophysiological assessment included the visual evoked potentials, corrected visual acuity, colour vision, mapping of the visual fields and ophthalmoscopy. Somatosensory evoked potentials were recorded with clavicular, cervical, mastoid and scalp electrodes. The results of these tests have been reported elsewhere. ${ }^{12} 13$ Standard immunological and 
haematological tests including an examination for acanthocytes were carried out.

\section{Biochemical tests}

A full routine biochemical screening was carried out on the blood of each patient. Urea, sodium, potassium, total protein, albumin, total globulins, calcium, phosphate, bilirubin, creatinine and uric acid were determined using standard clinical chemistry automated techniques. In some of the patients, iron and iron binding capacity was determined. Thyroxine and $\mathrm{T}_{3}$ uptake were determined by radioimmunoassay, cholesterol was determined enzymically using cholesterol oxidase and lipoproteins were determined using nephelometry. The following enzymes were determined in the patients' blood: lactate dehydrogenase and aspartate aminotransferase using the Scandinavian recommended methods, ${ }^{14}$ alkaline phosphatase using an automated version of the method of Kind and King. ${ }^{15}$ Lipoamide dehydrogenase was measured in the sera of representative patients and controls by the method of Pelly et al. ${ }^{16}$ Red cell transketolase was also determined. ${ }^{17}$ Urinary organic acids, ${ }^{18} 19$ amino acids, and oligosaccharides ${ }^{20}$ were measured in all patients.

\section{Biochemical investigations}

All patients had a fasting oral glucose tolerance test. $50 \mathrm{~g}$ D-glucose in water was administered and blood samples taken at $-15,0,15,30,60,90,120,150,180$ minutes for glucose and lactate determinations and at $0,30,90$, and 150 minutes for pyruvate and insulin assays. All urine passed during this test was pooled from each patient for organic and aminoacid analysis.

Thirteen of the patients had an oral alanine loading test to elucidate any abnormalities in pyruvate metabolism or gluconeogenesis. $500 \mathrm{mg} \mathrm{L-} \alpha$-alanine $/ \mathrm{kg}$ body weight were administered, in water, and blood samples were obtained as described for the glucose loading test. A group of six normal volunteers from the laboratory, age 21-37 years also had alanine and glucose loading tests under the same conditions as the patients. Whole blood pyruvate and lactate concentrations were determined using lactate dehydrogenase and a standard test kit (Boehringer (London)) and insulins were measured by radioimmunoassay at the Supraregional Assay Laboratory, Guildford, Surrey.

\section{Results}

\section{Clinical findings}

The main clinical findings for the 20 patients are shown below. Only the positive signs observed are shown. Normal intelligence 20/20; Cerebellar dysarthria 20/20; Cerebellar ataxia 20/20; Wheelchair-bound 20/20; Tendon reflexes absent in lower limbs 20/20; Extensor plantar reflexes 19/ 20; Posterior column loss 20/20; Pes cavus 17/20;
Radiological scoliosis $13 / 14$ (out of 14 radiographed); Cardiomyopathy on ECG 14/15 (out of 15 tested); Small handmuscle wasting 13/20; Optic atrophy $14 / 20$. Mean age of onset was 11.7 years and ranged from 5 to 25 years.

\section{Genetical analysis}

The 20 patients had 19 affected and 27 unaffected sibs. Consanguinity was present in two families. In no instance was a parent affected. Analysis of the pedigrees confirms that Friedreich's ataxia is an autosomal recessive disorder, and using the Weinberg proband method, ${ }^{21}$ a figure approaching 0.25 was reached. This implies recessive inheritance.

\section{Biochemical findings}

Routine clinical chemistry, haematology and immunology In general, values obtained for these parameters in the group of patients studied fell within the appropriate normal ranges. No abnormalities were detected in the urinary organic acids, aminoacids or oligosaccharides. Five patients out of 18 showed a low thiamine status as determined by red cell transketolase and two patients had very low values for red cell transketolase.

Results from the glucose and alanine loading tests are shown in figs 1 and 2 . A wide spread, illustrated by the standard error of the mean, was obtained when the results for each patient were plotted individually and one patient showed a typical diabetic response to the glucose load. This patient was omitted from the analysis presented here. Throughout the loading tests, the "zero" time sample was drawn immediately before the glucose or alanine was administered and so represents a true baseline value.

Analysis of figure 1 shows that the mean glucose levels in patients with Friedreich's ataxia were higher than those of controls at all times except prior to loading. There was evidence of an enhanced lactate response at times between 60 and 120 minutes post loading but the differences were not statistically significant. There was no difference in pyruvate response between the two groups. The insulin concentrations for the patients, however, were higher than control values throughout the test. The return to pre-load values was delayed in the patients by comparison with the controls.

No differences between controls and patients were observed as a result of oral $L-\alpha$-alanine loading (fig 2) and urinary organic acids remained normal throughout both glucose and alanine loading tests. 

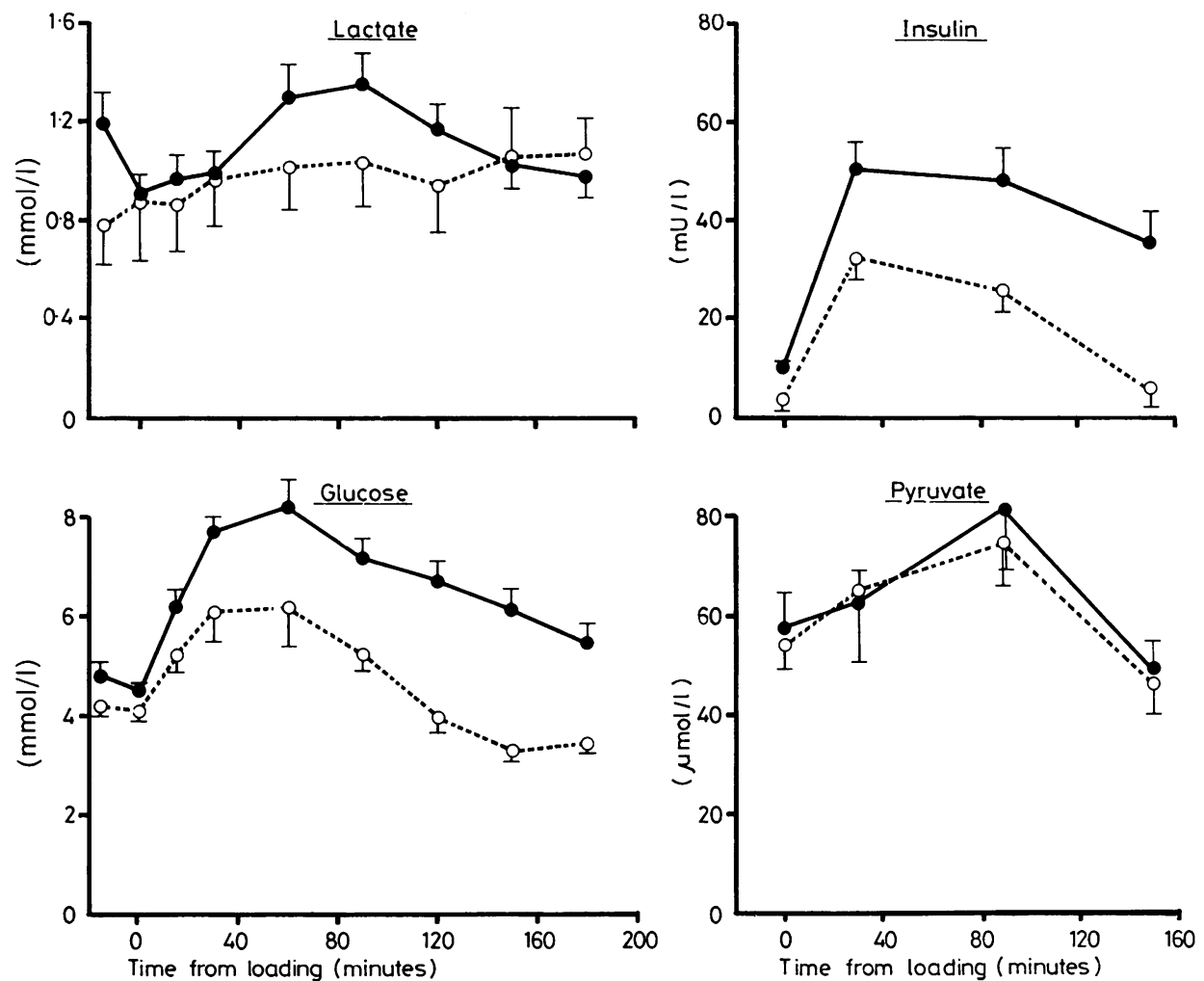

Fig 1 Response of plasma lactate, pyruvate, insulin and glucose to a glucose load $(1 \mathrm{~g} / \mathrm{kg}$ body weight $D$-glucose) in 18 patients with Friedreich's ataxia $(\bullet-\bullet)$ and 5 controls $(\bigcirc-\bigcirc)$. Two patients showing a diabetic response are omitted from the analysis. Data points show mean values and bars show standard error of the mean.

\section{Discussion}

The clinical findings in this study resemble those of Barbeau and his colleagues ${ }^{2} 32$ and confirm that Friedreich's ataxia is a clinically homogenous group characterised by a cerebellar ataxia occurring before the age of 20 years, initially in the lower limbs but ascending to involve the trunk and upper limbs. Other important clinical hallmarks are listed in the results section. Pes cavus, scoliosis and nystagmus are less frequent findings. The optic fundi were pale in 14 of the 20 patients examined. Using the ECG as evidence, jusi over half the patients were found to have signs of a cardiomyopathy.

Biochemical tests in this group of patients generally revealed few clues to the underlying primary defect in Friedreich's ataxia. Most of the standard biochemical parameters including those suggested as possibly abnormal as a result of the extensive work of the Quebec co-operative study of Friedreich's ataxia ${ }^{23}$ (bilirubin, amino acid, lipid and calcium metabolism) were normal in our patients. The amino acid data do not confirm the raised excretion of taurine and $\beta$-amino acids reported by Lemieux et al. ${ }^{23}$ The Technicon TSM analyser was the instrument used in our own work and that of Lemieux et al. Difficulties with the measurement of taurine may be encountered due to the low pKa of this compound because quantitative ion exchange with the cartridge resin used to load samples onto the column may not be achieved. This problem was overcome in the present work by direct injection, bypassing the cartridge. Cerebrospinal fluid amino acids were not studied because of the absence of an abnormal aminoaciduria in our patients.

Data obtained from the study of serum lipids and lipoproteins revealed no consistent trends although the number of patients for whom full data was obtained was small.

Red cell transketolase activity, which is indica- 

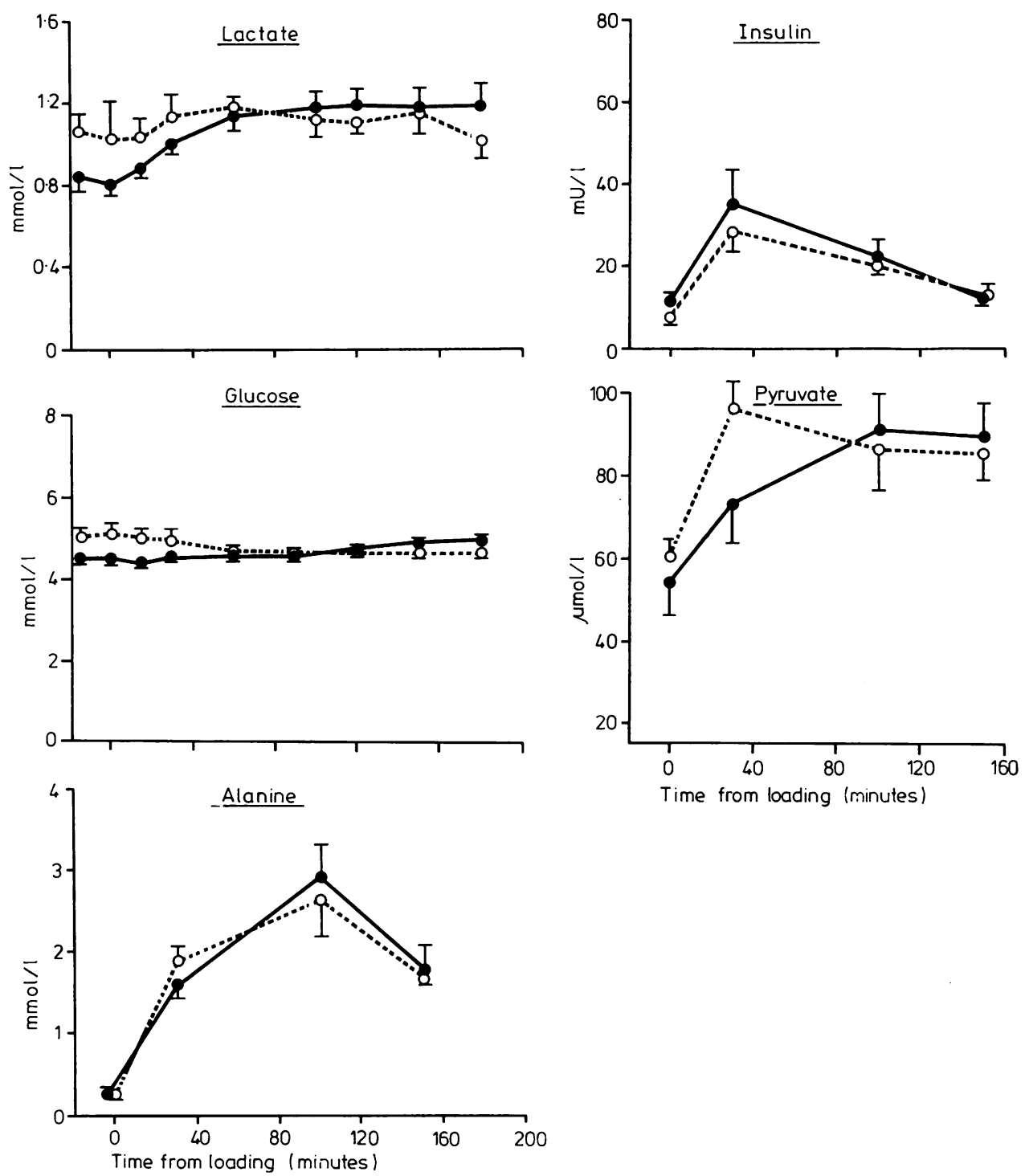

Fig 2 Response of plasma pyruvate, insulin, lactate, glucose and alanine to an alanine load

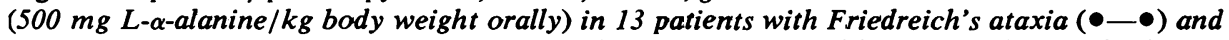
6 normal controls $(\mathrm{O}-\mathrm{O})$. Data points show the mean values and bars show the standard error of the mean.

tive of thiamine status, was very low in two of the patients studied. Enhanced response to thiamine stimulation of red cell transketolase was observed in five out of 18 patients. These findings may have some relevance to pyruvate metabolism in Friedreich's ataxia since thiamine is a cofactor for pyruvate dehydrogenase, the first component in the PDH complex, and further studies on the thiamine status of similar patients may be useful.

Some patients with Friedreich's ataxia have abnormal blood pyruvate concentrations after a glucose $\operatorname{load}^{562425}$ and this has been taken as indicative of a defect in pyruvate oxidation in the disease. This was not confirmed in the present study, all patients showing normal pyruvate re- 
sponses to an oral glucose tolerance test although a tendency towards a higher lactate response between 60-120 minutes was observed (fig 1). Similarly, in loading tests with L- $\alpha$-alanine which challenge pyruvate metabolism more directly, alanine being the immediate metabolic precursor of pyruvate, the response in blood pyruvate concentrations was normal although blood alanine levels increased more than tenfold during the test both in patients and controls. In the alanine load test, there was no stimulation of blood glucose or insulin levels and it is possible that the challenge to gluconeogenesis from an oral rather than an intravenous load was insufficient for a response to be observed. ${ }^{26}$ Urinary organic acids showed no abnormalities even during the alanine load test, in contrast with the abnormal qualitative and quantitative patterns observed in patients with gross deficiencies of the pyruvate dehydrogenase complex and other disorders presenting as congenital lacticacidoses ${ }^{27}$ including those with deficient activity of the lipoamide dehydrogenase $\left(E_{3}\right)$ component of the 2-oxoacid dehydrogenase complexes.

Some children with intermittent and progressive ataxia due to putative partial defects in the tricarboxlic acid cycle ${ }^{28}$ also show urinary organic acid abnormalities which are accentuated during oral alanine load tests. It is possible, however, that in the presence of only $50 \%$ of normal PDH activity as postulated by Kark et $a l,{ }^{6}$ or in the presence of a regulatory defect, such as PDH phosphatase deficiency there would be no overt abnormal organic aciduria.

It is clear from the results obtained that there is no reduction in pyruvate oxidation in patients with Friedreich's ataxia when compared to controls in contrast with results reported elsewhere ${ }^{56}$ and it is thus unlikely that there is any generalised defect in pyruvate oxidation. This is supported by the normal activity of serum lipoamide dehydrogenase in all of the patients studied in the present work. This is in contrast to the work of Barbeau and his colleagues who reported that most patients with Friedreich's ataxia studied by them had reduced serum lipoamide dehydrogenase due apparently to a deficiency of an undefined activator contained in serum high density lipoproteins. ${ }^{329}$ Rodriguez-Budelli et $a l^{30}$ also indicate that lipoamide dehydrogenase may be abnormal in this disorder. The assay conditions used in the present work differ in detail from those of other workers cited. Buffer composition and substrate concentration were different. In addition, our results are expressed per $\mathrm{ml}$ serum rather than per unit protein so that direct comparison is difficult. However, the results obtained on the patients did not differ from normal.

The results of the oral glucose tolerance test with respect to blood glucose and insulin responses are of potentially greater interest. It is well known that some $40 \%$ of patients with "classical" Friedreich's ataxia show chemical or clinical glucose intolerance. $^{31}$ In the present work in which patients with clinical diabetes mellitus were specifically excluded, the patients considered as a group showed impaired glucose tolerance although at a lower level than that observed in patients with type I diabetes. However, all the patients considered as a group showed a sustained hyperinsulinaemic response to an oral glucose tolerance test. A hyperinsulinaemic response to a glucose tolerance test by patients with Friedreich's ataxia but with normal pancreatic cells and insulin release has been observed by others. ${ }^{32}$ It is also evident, however, that the sustained and enhanced response is due to a much slower uptake and utilisation of glucose than normal as demonstrated by the glucose response to the load and that this is not evidence of latent or subclinical diabetes in patients with Friedreich's ataxia as implied elsewhere. It seems that there is a defect in the utilisation or uptake of glucose in the disease and this reduced ability of organs and cells to take up and utilise substrates may be a more generalised defect applying also, for example, to pyruvate.

It is concluded from the present work that in patients with well defined Friedreich's ataxia, previously reported biochemical abnormalities ${ }^{2}{ }_{4}$ do not occur. There is no generalised defect in the oxidation of pyruvate or in lipoamide dehydrogenase but there is an abnormality in the uptake and utilisation of glucose and probably other metabolites by organs or cells that may be related to a generalised membrane defect. This warrants further detailed investigation.

We acknowledge the technical assistance of Mrs PR Jennings and thank Mrs M Bravery for coordinating the admissions of the patients. We are thankful for help from Mrs J Walker of the London Hospital Medical College with obtaining specimens for lipoamide dehydrogenase assay. We are grateful to several volunteers from the laboratories at the Clinical Research Centre who subjected themselves to glucose and alanine loading tests.

The work would not have been possible without the co-operation of the nursing staff of Haldane Ward. We acknowledge the interest of Dr RWE 
Watts. We thank Dr M Rinsler and Professor V Marks for arranging the insulin assays.

The nature of the investigations was explained to all patients in advance of their admission to the ward and their consent obtained. Before each loading test, the procedure was explained at greater length. The work was approved by the Ethical Committee of the Clinical Research Centre and Northwick Park Hospital.

\section{References}

1 Andermann A, Remillard GM, Goyer C, Blitzer L, Andermann F, Barbeau A. Genetic and family studies in Friedreich's ataxia. Can J Neurol Sci 1976; 3:287-301.

2 Barbeau A. Friedreich's ataxia, 1978-An overview. Can J Neurol Sci 1978; 5:161-5.

3 Barbeau A. Friedreich's ataxia, 1979-An overview. Can J Neurol Sci 1979; 6:311-9.

4 Kark RAP, Blass JP, Engel WK. Pyruvate oxidation in neuromuscular diseases-evidence of a genetic defect in two families with the clinical syndrome of Friedreich's ataxia. Neurology (Minneap) 1974; 24:964-71.

5 Blass JP, Kark RAP, Mennon NK. Low activities of the pyruvate and oxoglutarate dehydrogenase complexes in five patients with Friedreich's ataxia. New Engl J Med 1976; 295:62-7.

6 Kark RAP, Rodriguez-Budelli M, Blass JP. Evidence for a primary defect in lipoamide dehydrogenase in Friedreich's ataxia. Adv Neurol 1978; 21:163-80.

7 Melancon SB, Potier M, Dallaire L, et al. Lipoamide dehydrogenase in Friedreich's ataxia fibroblasts. Can J Neurol Sci 1978; 5:115-8.

8 Barbeau A, Melancon S, Butterworth RF, Filla A, Izumi K, Ngo TT. Pyruvate dehydrogenase complex in Friedreich's ataxia. Adv Neurol 1978; 21:203-17.

9 Huang YS, Nestruck AC, Barbeau A, Bouchard JP, Daingon J. Plasma lipids and lipoproteins in Friedreich's ataxia and familial spastic ataxiaevidence for an abnormal composition of high density lipoproteins. Can J Neurol Sci 1976; 5: 149-56.

10 Barbeau A, Breton G, Lemieux B, Butterworth RF. Bilirubin metabolism-preliminary investigation. Can J Neurol Sci 1976; 3:365-72.

11 Barbeau A. Friedreich's ataxia 1980. An overview of the physiopathology. Can J Neurol Sci 1980; 7:455-68.

12 Carroll WM, Kriss A, Baraitser M, Barratt G, Halliday AM. The incidence and nature of visual pathway involvement in Friedreich's ataxia. Brain 1980; 103:413-34.

13 Jones SJ, Baraitser M, Halliday AM. Peripheral and central somatosensory nerve conduction defects in Friedreich's ataxia. J Neurol Neurosurg Psychiatry 1980; 43:495-503.

14 The committee on enzymes of the Scandinavian
Society for clinical chemistry and clinical physiology. Recommended methods for the determination of 4 enzymes in blood. Scand J Clin Lab Invest 1974; 33:291-306.

15 Kind PRN. King EJ. Estimation of plasma phosphatase by determination of hydrolysed phenol with aminoantipyrine. J Clin Path 1954; 7:322-6.

16 Pelly JW, Little GH, Linn TC, Hall FF. Lipoamide dehydrogenase in serum, a preliminary report. Clin Chem 1976; 22:275-7.

17 Williams D. Methods for estimation of 3 vitamin dependent red cell enzymes. Clin Biochem 1976; 9:252-5

18 Chalmers RA, Watts RWE. The quantitative extraction and gas liquid chromatographic determination of organic acids in urine. Analyst 1972; 97:958-67.

19 Lawson AM, Chalmers RA, Watts RWE. Urinary organic acids in man. 1. Normal patterns. Clin Chem 1976; 22:1283-7.

20 Purkiss $\mathbf{P}$, Hughes RC, Watts RWE. Screening for oligosaccharides in urine, a quantitative procedure. Clin Chem 1978; 24:669-74.

21 Weinberg W. Weitere Beiträge zur Theorie der Vererbung. 4. Ueber Methode und Fehlerquellen der Untersuchung auf Mendelsche Zahlen beim Menschen. Arch $f$ Rassen-U Gesellsch-Biol Leipz U Berl 1912; 9:165-74.

22 Geoffroy G, Barbeau A, Breton G et al. Clinical description and roentgenologic evaluation of patients with Friedreich's ataxia. Can J Neurol Sci 1976; 3:279-86.

23 Lemieux B, Barbeau A, Beroniade V, et al. Amino acid metabolism in Friedreich's ataxia. Can $J$ Neurol Sci 1976; 3:373-8.

24 Barbeau A, Butterworth RF, Breton G, et al. Pyruvate metabolism in Friedreich's ataxia. Can J Neurol Sci 1976; 3:379-88.

25 Stumpf DA, Parks JF. Friedreich ataxia II. Normal kinetics of lipoamide dehydrogenase. Neurology (Minneap) 1979; 29:820-6.

26 Fernandez J, Blom W. The intravenous Lalanine tolerance test as a means for investigating gluconeogenesis. Metabolism 1974; 23:1149-56.

27 Chalmers RA, Lawson AM, Borud O. Gas chromatographic and mass spectrometric studies on urinary organic acids in a patient with congenital lacticacidosis due to pyruvate decarboxylase deficiency. Clin Chim Acta 1977; 77:117-24.

28 Chalmers RA, Lawson AM, Purkiss P, Watts RWE. Screening for organic acidurias and amino acidopathies in newborns and children. $J$ Inher Metab Dis 1980; 3:27-43.

29 Filla A, Butterworth RF, Geoffroy G, Lemieux B, Barbeau A. Serum and platelet lipoamide dehydrogenase in Friedreich's ataxia. Can J Neurol Sci 1978; 8:111-4.

30 Rodriguez-Budelli M, Kark P. Kinetic evidence for a structural abnormality of lipoamide dehydrogenase in 2 patients with Friedreich's 
ataxia. Neurology (Minneap) 1978; 28:1283-6.

31 Thoren C. Diabetes mellitus in Friedreich's ataxia. Acta Paediat. (Upps) 1962; 51: sup 135: $239-47$.
32 Shapcott D, Melancon S, Butterworth RF, et al. Glucose and insulin metabolism in Friedreich's ataxia $1976 ; 3: 361-4$. 